\title{
Influence of post-hydrogenation upon electrical, optical and structural properties of hydrogen-less sputter-deposited amorphous silicon
}

\author{
S. Gerke a,*, H.-W. Becker ${ }^{\text {b }}$, D. Rogalla ${ }^{\text {b }}$, F. Singer ${ }^{\text {a }}$, N. Brinkmann ${ }^{\text {a }}$, S. Fritz ${ }^{\text {a }}$, A. Hammud ${ }^{\text {a }}$, P. Keller ${ }^{\text {a }}$, D. Skorka ${ }^{\text {a }}$,

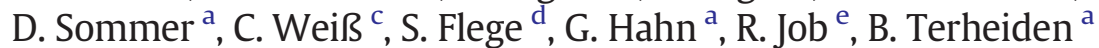 \\ a Department of Physics, University of Konstanz, Konstanz, 78457, Germany \\ ${ }^{\mathrm{b}}$ RUBION - Central Unit for Ion Beams and Radioisotopes, University of Bochum, Bochum, 44780, Germany \\ c Fraunhofer Institute for Solar Energy Systems ISE, Heidenhofstraße 2, 79110 Freiburg, Germany \\ d Department of Materials Science, TU Darmstadt, Darmstadt 64287, Germany \\ e Department of Electrical Engineering and Computer Science, Münster University of Applied Sciences, Steinfurt 48565, Germany
}

Keywords:

AFM

Amorphous silicon

Hydrogen depth profiling

NRRA

Post-hydrogenation

Raman

RF sputter-deposition

\begin{abstract}
A B S T R A C T
Amorphous silicon (a $\mathrm{Si}$ ) is common in the production of technical devices and can be deposited by several techniques. In this study intrinsic and doped, hydrogen less amorphous silicon films are RF magnetron sputter deposited and post hydrogenated in a remote hydrogen plasma reactor at a temperature of $370{ }^{\circ} \mathrm{C}$. Secondary ion mass spectrometry of a boron doped (p) a Si layer shows that the concentration of dopants in the sputtered layer becomes the same as present in the sputter target. Improved surface passivation of phosphorous doped $5 \Omega \mathrm{cm}, \mathrm{FZ}$, (n) c Si can be achieved by post hydrogenation yielding a minority carrier lifetime of $\sim 360 \mu \mathrm{s}$ finding an optimum for $\sim 40 \mathrm{~nm}$ thin films, deposited at $325^{\circ} \mathrm{C}$. This relatively low minority carrier lifetime indicates high disorder of the hydrogen less sputter deposited amorphous network. Post hydrogenation leads to a decrease of the number of localized states within the band gap. Optical band gaps (Taucs gab as well as $E_{04}$ ) can be determined to $\sim 1.88 \mathrm{eV}$ after post hydrogenation. High resolution transmission electron microscopy and optical Raman investigations show that the sputtered layers are amorphous and stay like this during post hydrogenation. As a consequence of the missing hydrogen during deposition, sputtered a Si forms a rough surface compared to CVD a Si. Atomic force microscopy points out that the roughness decreases by up to $25 \%$ during post hydrogenation. Nuclear resonant reaction analysis permits the investigation of hydrogen depth profiles and allows determining the diffusion coefficients of several post hydrogenated samples from of a model developed within this work. A dependency of diffusion coefficients on the duration of post hydrogenation indicates trapping diffusion as the main diffusion mechanism. Additional Fourier transform infrared spectroscopy measurements show that hardly any interstitial hydrogen exists in the post hydrogenated a Si layers. The results of this study open the way for further hydrogen diffusion experiments which require an initially unhydrogenated drain layer.
\end{abstract}

\section{Introduction}

Amorphous silicon (a $\mathrm{Si}$ ) is a common functional material for the production of electronic devices like diodes, thin film transistors (TFTs), liquid crystal displays (LCDs), optical sensors and solar cells [1 6]. Especially in heterojunction silicon solar cells an intrinsic and hy drogenated a Si interlayer plays the key role for high efficiencies [6].

A common industrial standard process for deposition of hydrogenat ed amorphous silicon (a $\mathrm{Si}: \mathrm{H}$ ) is plasma enhanced chemical vapor deposition (PECVD). For this kind of process, the flammable and toxic gas silane $\left(\mathrm{SiH}_{4}\right)$ is needed.

\footnotetext{
* Corresponding author.

E-mail address: sebastian.gerke@uni-konstanz.de (S. Gerke).
}

Silane can be avoided completely by the application of radio fre quency magnetron sputter deposition (RFSD). Although it is known since the late 1970s (Refs. $[7,8]$ ) that it is also possible to sputter a $\mathrm{Si}$ :H layers, it was only recently published that surface passivation of crystalline silicon (c Si) substrates by RFS deposited a Si:H layers is possible [9 11]. According to these publications the quality of surface passivation of RFS deposited films was similar to PECV deposited ones. To achieve surface passivating a Si:H layers directly during RFSD, $\mathrm{Ar}$ has to be mixed with only $2 \%$ of hydrogen [11]. More common in the field of RFSD layers for c Si surface passivation are aluminum oxide $\left(\mathrm{Al}_{2} \mathrm{O}_{3}\right)$ (Refs. [12 14]) as well as silicon carbide ( $\mathrm{SiC}_{\mathrm{x}}$ ) (Refs. [15 17]) or silicon nitride (SiN) (Refs. [18,19]).

The usage of the process gas silane in a PECVD reactor allows only deposition of hydrogenated a Si layers. In contrast, RFSD technology 
uses a solid target consisting solely of the material intended to be deposited [3].

Gloger et al. demonstrated that surface passivation of a c Si wafer by an (i) a Si:H layer, destroyed by a high temperature treatment, could be recovered by annealing in an atmosphere containing hydrogen radicals [20]. It can therefore be assumed that it is possible to achieve surface passivation by hydrogenating a hydrogen less a Si layer in a MIRHP (microwave induced remote hydrogen plasma) reactor [20]. Analyzing surface passivation of c Si wafers starting from hydrogen less a Si layers allows investigation of hydrogen diffusion within the a Si layer and the corresponding influence of the amorphous network. An unhydrogenated a Si layer can also be used as a hydrogen drain layer for investigations like diffusion or effusion analysis of other films or materials, as described e. g. in Refs. [21]and [22]. A thorough knowledge of the characteristics of such a drain layer is of fundamental importance for these investigations.

\section{Experimental details}

\section{1. $R F$ magnetron sputtering and post hydrogenation setups}

Sputtering of doped ( $\mathrm{p}$ type) and intrinsic silicon targets took place in an RF magnetron sputtering system (AJA ATC 2200) at a pressure of 2 mTorr using $\mathrm{Ar}$ as process gas. The p type $\mathrm{c}$ Si target used in this study is doped by boron and shows a resistivity of $\sim 1.6 \Omega \mathrm{cm}$ (in house measured by the 4 Point Probe method [23]). Amorphous sil icon films are RFS deposited on phosphorous doped (n type, $5 \Omega \mathrm{cm}$, $250 \mu \mathrm{m},<100>$ oriented) float zone (FZ) c Si wafers with a chemically polished surface. Wafers are dipped in aqueous HF solution prior to RFSD to remove the native silicon oxide. Several samples are deposited varying layer thickness and deposition temperature to investigate the morphology and the influence of the following post hydrogenation on passivation quality.

Investigations described in Section 3 are based on optimal RFSD conditions with samples prepared at a process temperature of $325^{\circ} \mathrm{C}$ and a Si layer thicknesses of $\sim 40 \mathrm{~nm}$ as outlined in Section 3.2.

The post hydrogenation processes used for the following investiga tions take place in a MIRHP reactor at a hydrogen pressure of $\sim 1000$ mTorr and a temperature of $370{ }^{\circ} \mathrm{C}$ [24].

References [24 27] describe the possibility of a post hydrogenation step of initially hydrogenated (i) a Si:H by a direct plasma. Tests using a PlasmaLab 100 parallel plate PECVD reactor from Oxford Instruments, applying direct hydrogen plasma, led to a removal of the RFS deposited a Si layer within a short time. The chemical stress and the following disorder of Si Si bonds supported this etching reaction. In case of using the MIRHP reactor, no etching was detected due to the remote plasma operation.

The post hydrogenation step involves thermal and hydrogen treatment within the period $t_{t}$, starting with the ignition of the hydrogen remote plasma and ending with switching off the plasma with immediate unloading of the samples from the MIRHP reactor.

\subsection{Passivation quality}

Passivation quality and evaluation during post hydrogenation of RFS deposited a Si:H is done by means of effective minority carrier lifetime $\left(\tau_{\text {eff }}\right)$ measurements. These are carried out at room temperature $\left(\sim 25^{\circ} \mathrm{C}\right)$ via microwave detected photo conductance decay measure ments ( $\mu$ PCD) using a Semilab WT 2000 with a spatial resolution of $250 \mu \mathrm{m}$ and bias light of 1 sun. Spatially resolved $\tau_{\text {eff }}$ data are providing detailed information about the local influence of the post hydrogenation and the homogeneity of the film. Measurements are cross checked via $\tau_{\text {eff }}$ deduction from transient and quasi steady state photo conductance decay (WCT 120, Sinton Instruments), also at $\sim 25^{\circ} \mathrm{C}$.

\subsection{Microscopic investigation}

Microscopic investigations by high resolution transmission electron microscopy (HR TEM) using a "JEOL JEM 2200FS" yield detailed infor mation about the structure of the sample. Also diffraction patterns are determined by two dimensional fast Fourier transformation (2D FFT) for further investigations about the periodicity of the a Si atoms compared to c Si [28].

Surface roughness of RFS deposited (i) and (p) a Si layers is analyzed by atomic force microscopy (AFM) [29]. AFM analyses are done using an "Asylum Research MFP 3D" in a non contact mode by scanning a $(1 \times 1) \mu \mathrm{m}^{2}$ area with $2^{16}$ points $(256 \times 256)$.

\subsection{Raman investigation}

A less extensive examination of a possible crystallization during heat treatment, without the effort of HR TEM investigations, is Raman spectroscopy [30]. This non destructive characterization method allows a fast investigation of the Raman crystallinity. Raman investigations are performed using a "WITec alpha300" with laser wavelength of $488 \mathrm{~nm}$ and $100 \times$ magnification.

Raman investigation allows determining the presence of amorphous (a Si), microcrystalline ( $\mu \mathrm{Si}$ ), and crystalline silicon (c Si) on the base of corresponding vibration modes of the Raman shift $[3,30]$. The uniform bond structure and the limited density of states of c Si yield a sharp Raman band width of the TO phonon band with a center of $521 \mathrm{~cm}^{-1}[31]$. Losing structural uniformity leads to a TO center shift to lower wavenumbers and a smoothing of the TO peak. $\mu$ Si till example provides a peak center at $510 \mathrm{~cm}^{-1}$ [32]. The disordered network of the amorphous structure yields the excitation of other modes. The sharp c Si TO Raman peak broadens with a center of around $470 \mathrm{~cm}^{-1}$. In addi tion to this TO phonon band, three more phonon band modes appear:

- $150 \mathrm{~cm}^{-1}$ (transverse acoustic, TA),

- $300 \mathrm{~cm}^{-1}$ (longitudinal acoustic, LA),

- $380 \mathrm{~cm}^{-1}$ (longitudinal optic, LO).

Note that in order to avoid laser induced crystallization during Raman measurements, the laser power has to be below a threshold of $1.5 \mathrm{~mW}$ for the sputtered a $\mathrm{Si}$ in comparison to $4 \mathrm{~mW}$ of PECVD a Si [31,33]. The threshold of $1.5 \mathrm{~mW}$ is determined by a laser power meter (COHERENT FieldMaster GS) and equates to a power density corresponding to the laser spot size of $0.27 \mathrm{~mW} / \mu^{2}$.

\subsection{Ellipsometry}

Determination of the RFS deposited layer thickness and other optical properties, like absorption coefficient $\alpha$ and determination of the optical band gap $E_{g}$ takes place using spectral ellipsometry measurements in the wavelengths range from $3002500 \mathrm{~nm}$ (J. A. Woollam V Vase 2000 ellipsometry unit).

Plotting the absorption coefficient $\alpha$ as a function of photon energy $\hbar \omega, E_{g}$ can be estimated to $E_{\text {Tauc }}$ by using Tauc's equation [34 36]. The band gap of amorphous silicon is about $1.8 \mathrm{eV}$ and blurred by defect states without abrupt band edges like c Si $(\sim 1.12 \mathrm{eV})$ has $[37,38]$. According to this, a common way estimating the band gap of a $\mathrm{Si}$ is the so called $E_{04}$ band gap. $E_{04}$ is defined as the energy for which $\alpha=$ $10^{4} \mathrm{~cm}^{-1}[37]$.

\subsection{Hydrogen depth profiling and bonding structures}

Nuclear resonant reaction analysis (NRRA) is a powerful, but not a common method, to obtain information about hydrogen distribution with depth in an a Si layer. Nevertheless, there are some published hy drogen depth profiles of a Si:H layers measured by NRRA[3,39 41].

NRR analyses are carried out using a dynamitron tandem accelera tor detecting all hydrogen isotopes [42]. Averages of NRRA measured 
hydrogen concentration in RFS deposited a Si layers are calculated by integration of the measured hydrogen depth profile of the layers, starting after the common surface peak and stopping at the a Si/c Si interface.

NRRA, also known as ${ }^{15} \mathrm{~N}$ profiling technique, is based on nuclear re action of a nitrogen isotope $\left({ }^{15} \mathrm{~N}\right)$ with a hydrogen atom. An accelerated ${ }^{15} \mathrm{~N}$ isotope reacts with a hydrogen atom to a carbon $\left({ }^{12} \mathrm{C}\right)$ and a helium $\left({ }^{4} \mathrm{He}\right)$ isotope. This reaction also emits a detectable $\gamma$ ray at an energy level of $4.43 \mathrm{MeV}$ [39 45]. The full reaction equation reads:

$15 \mathrm{~N}+1 \mathrm{H} \rightarrow 12 \mathrm{C}+4 \mathrm{He}+\gamma(4.43 \mathrm{MeV})$.

Counting $\gamma$ rays of a sample and adjusting them to the background radiation leads to a quantitative value which can be compared to $\gamma$ rays of a known (i) a Si:H standard like the certified reference mate rial BAM S110 [46]. From this comparison the content of hydrogen atoms per $\mathrm{cm}^{3}$ can be determined. Considering the atomic density of sil icon of $\sim 5 \cdot 10^{22}$ atoms $/ \mathrm{cm}^{3}$ (Ref. [47]), the hydrogen concentration can be calculated. Moreover, the reaction energy is an isolated and very narrow resonance at a beam energy of $6.385 \mathrm{MeV}$ [48]. Assuming a stopping power of the amorphous layer of $1.38 \mathrm{keV} / \mathrm{nm}$ (Ref. [39]), a corresponding increase of the beam energy enables measuring a hydro gen depth profile.

More common than NRRA are secondary ion mass spectrometry (SIMS) measurements, because this technique allows a simultaneous detection of further elements included in a sample $[43,44]$ SIMS mea surements were performed with a sector field instrument (Cameca ims5f) using optimized conditions for the detection of boron in silicon. According to Refs. $[43,44]$ oxygen primary ions $\mathrm{O}_{2}^{+}$with $2.5 \mathrm{keV}$ ener gy) are used in combination with the detection of positive secondary ions. The raster size was $250 \times 250 \mu \mathrm{m}^{2}$, the detection area comprised the inner $150 \mu \mathrm{m}$ (diameter). The content of boron atoms per $\mathrm{cm}^{3}$ was determined by comparing with a known standard.

Another method getting information about the overall hydrogen concentration without detailed information about the depth distribu tion is Fourier transform infrared spectroscopy (FTIR). Based on the absorbance $A_{\text {film }}$ of a layer (thickness: $d_{\text {fim }}$ ) coating a carrier substrate, the effective absorption coefficient $\alpha_{\text {eff }}$ can be obtained by FTIR measurements, according to Eqs. (2) and (3)[49].

$A_{\text {film }} \quad A_{\text {total }}-A_{\text {substrate }}$

$\alpha_{\text {eff }} \frac{A_{\text {film }}}{d_{f i l m} \log _{10} e}$

Prior to the calculation of $\alpha_{\text {eff }}$ from the absorption intensity in the se lected bandwidth of wavenumbers, a baseline correction of the FTIR data, i.e. subtracting the Drude term, has to be carried out. The intensity of an interesting bandwidth of wavenumbers $(\omega)$ can be calculated by integrating [35].

Langford et al. described a method and gave coefficients to calculate the $\mathrm{Si} \mathrm{H}\left(2000 \mathrm{~cm}^{-1}\right)$ and $\mathrm{Si} \mathrm{H}_{2}\left(2090 \mathrm{~cm}^{-1}\right)$ bond densities and therefore the sum $\left(N_{H}\right)$ of these $\mathrm{Si} \mathrm{H}_{\mathrm{x}}$ bonds, according to Eq. (4)[50]. The coefficients are: $c_{2000}=9 \cdot 10^{19} \mathrm{~cm}^{-2}$ for $\mathrm{Si} \mathrm{H}$ bonds and $c_{2090}=$ $2.2 \cdot 10^{20} \mathrm{~cm}^{-2}$ for $\mathrm{Si} \mathrm{H}_{2}$ bonds.

$N_{H} \quad c_{2000} I_{2000}+c_{2090} \quad I_{2090}$

Hydrogen bond structures of RFSD a Si layers are analyzed in the de scribed way by using a "Bruker IFS 113v" and a "Bruker Vertex 80" spectrometer.

\subsection{Post hydrogenation}

Contrary to PECV deposited a Si:H, RFS deposited and post hydrogenated a Si:H does not have a constant hydrogen concentra tion across the layer. Improving surface passivation of an initially unhydrogenated a Si layer during a post hydrogenation step, hydrogen has to diffuse through the film to saturate defects at the a Si/c Si inter face. Defects in the a Si bulk trap the hydrogen and hamper the diffusion within and through the layer. According to Ref. [51], the time dependent diffusion can be approximated by a complementary error function.

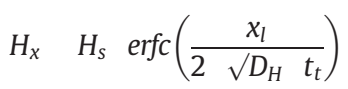

The hydrogen content $H_{x}$ at depth $x_{l}$ depends on the surface concen tration $H_{s}$, the duration of the post hydrogenation step $t_{t}$ and the diffusion coefficient of hydrogen in a $\mathrm{Si} D_{H}$.

To compare a Si layers of different thicknesses regarding post hydrogenation, the normalized timescale for the post hydrogenation is set to $[\mathrm{min} / \mathrm{nm}]$.

\section{Results and discussion}

\subsection{Doping of sputter deposited amorphous silicon}

Doping of a Si during RFS deposition occurs using a lightly doped c Si sputter target $\left(1.6 \Omega \mathrm{cm}, 9.14 \cdot 10^{15} \mathrm{~cm}^{-3}\right)$. Depth profiles of boron and silicon through a $154 \mathrm{~nm}$ thick RFS deposited (p) a Si layer measured by SIMS (Ref. [43,44,52,53]) are shown in Fig. 1. The investi gation shows that beyond the transient region at the surface boron is homogenously embedded in the layer during RFSD. Furthermore, the SIMS measurements show that the average content of boron included in the RFSD (p) a Si is $\sim 9.31 \cdot 10^{15} \mathrm{~cm}^{-3}$. Within the measurement accu racy this content is equal to the average content of the $\mathrm{c}$ Si sputter target.

Lateral conductivity $(\gamma)$ (Ref. [54]) measurements (Keithley, 6517A Electrometer) of a $100 \mathrm{~nm}$ thick (p) a Si layer deposited on quartz glass yield that conductance directly after deposition is $4.31 \cdot 10^{-7} \mathrm{~S} / \mathrm{cm}$. This value is three orders of magnitude higher compared to PECV deposited (p) a Si:H exhibiting a comparable boron concentration [55]. After $100 \mathrm{~min} / \mathrm{nm}$ of post hydrogenation, a conductivity of the RFS deposited (p) a Si is no longer detectable within measurement accuracy $\left(\gamma \ll 1 \cdot 10^{-10} \mathrm{~S} / \mathrm{cm}\right)$.

This leads to the suggestion that conductance is driven more by carrier trapping via localized states in the band gap than by the boron doping. As investigations of the band gap in Section 3.5 have shown, the density of localized states within the band gap decreases during post hydrogenation. This decrease therefore leads to a decrease of conductivity.

Moreover, hydrogen saturates defects and dangling bonds as well as dopants while conductivity further decreases [3,52].

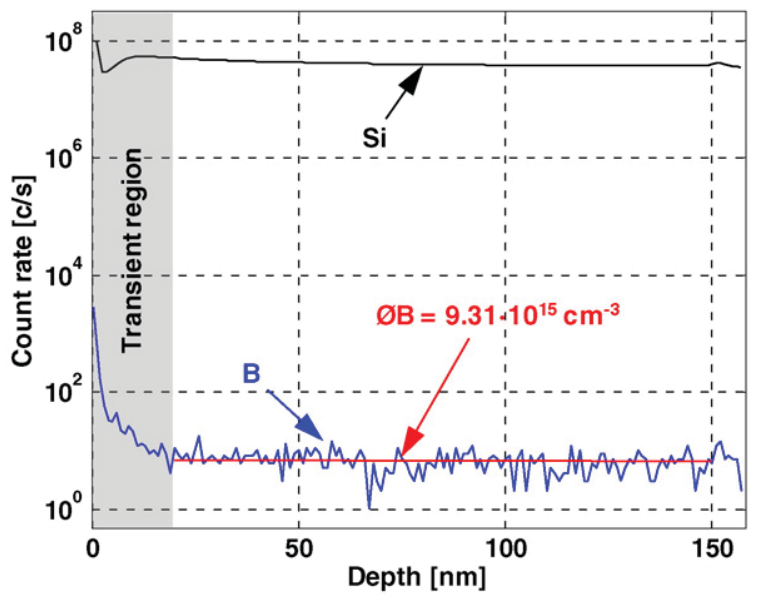

Fig. 1. Boron and silicon depth profiles of a $154 \mathrm{~nm}$ thick RFS-deposited (p) a-Si layer measured by SIMS. 


\subsection{Passivation quality}

Passivation of the c Si surface occurs at the a Si/c Si interface by Si Si bonds and additional hydrogen induced saturation of dangling bonds. Hydrogen less a Si layers do not passivate c Si surfaces because of the missing saturation of dangling bonds.

Using hydrogen less RFS deposited a $\mathrm{Si}$ in combination with additional post hydrogenation, the hydrogen has to diffuse through the a Si layer first before reaching the defect sites at the a $\mathrm{Si} / \mathrm{c} \mathrm{Si}$ interface. Evaluation of surface passivation and its changes during post hydrogenation gives information about the status of hydrogen dif fusion and in turn about the electronic quality of the a Si.

A measure for surface passivation quality is minority carrier lifetime $\left(\tau_{\text {eff }}\right)[52,56,57]$. Fig. 2 shows the evaluation of surface passivation qual ity of a $38 \mathrm{~nm}$ thick RFS deposited (p) a Si layer during post hydrogenation at $370{ }^{\circ} \mathrm{C}$ for up to $450 \mathrm{~min} / \mathrm{nm}(\sim 12 \mathrm{~d})$.

Interpolation between measured data points shows that surface passivation rises within the first $100 \mathrm{~min} / \mathrm{nm}$ of post hydrogenation to up to nearly $90 \%$ of the final state. The mentioned interpolation is done by piecewise cubic hermite interpolating polynomial (PCHIP) evolution [58].

Furthermore, Fig. 2 shows that it takes another $250 \mathrm{~min} / \mathrm{nm}$ post hydrogenation step to reach the final passivation state. Because of an achievement of $\sim 90 \%$ of the maximal reachable surface passivation dur ing the MIRHP process and the acceptable duration of $100 \mathrm{~min} / \mathrm{nm}$ of post hydrogenation in the lab, this duration is set as standard post hydrogenation time ( $t_{t}$ in Eq. (6)) for further investigations.

Spatially resolved $\mu \mathrm{PCD} \tau_{\text {eff }}$ measurement indicates a high lateral uni formity on the wafer. The standard deviation $(\sigma)$ in $\tau_{\text {eff }}$ of RFS deposited a Si is $<7 \%$ and similar to PECV deposited samples. This indicates a uni form post hydrogenation of the samples as well as a homogenous RFS deposition which is a direct function of the thickness dependent post hydrogenation time as pointed out in Fig. 2.

Compared to initially hydrogenated layers by RFSD (Ref. [10,11]) as well as PECVD (Ref. [52 59]), the absolute passivation quality of initially unhydrogenated a Si even after hydrogenation is very low. In this study, $\tau_{\text {eff }}$ rises to a maximum of $\sim 360 \mu$ s during $100 \mathrm{~min} / \mathrm{nm}$ of post hydrogenation at $370^{\circ} \mathrm{C}$. According to interpolation of Fig. 2, the maximum of $\tau_{\text {eff }}$ can be estimated to reach $\sim 400 \mu$ s.

A reason for the comparatively low minority carrier lifetime is the missing hydrogen induced reorganization of the amorphous network during deposition. This leads to a higher disorder of the amorphous net work and to more defects.

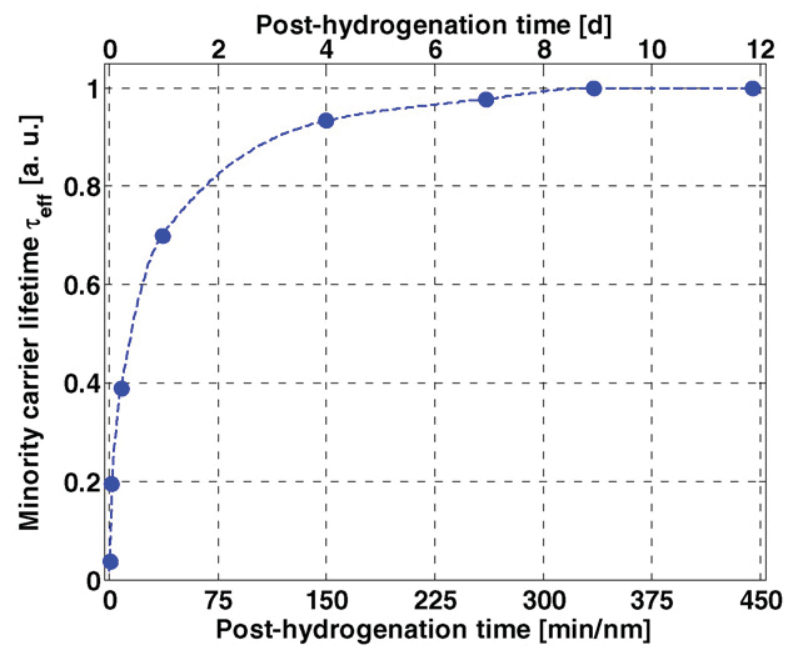

Fig. 2. Evaluation of surface passivation and its saturation during post-hydrogenation. Line interpolated by piecewise cubic hermite interpolating polynomial evolution as a guide to the eye.
Zhang et al. pointed out (Ref. [11]) that passivation quality of hydro genated RFS deposited (i) a Si:H depends on deposition temperature as well as layer thickness. This correlates to findings of PECVD a Si:H $[52,60]$.

As pointed out in Fig. 3(a), minority carrier lifetime of $38 \mathrm{~nm}$ thick unhydrogenated (p) as well as (i) a Si layers depends on deposition temperature and reaches up to $\sim 350 \mu$ s. For both types a maximum life time can be determined for a deposition temperature of $325^{\circ} \mathrm{C}$ while further increase of deposition temperature leads to a decrease in passiv ation quality. This correlates to the mentioned findings for directly hy drogenated RFSD (i) a Si:H [11]. Moreover, it can be seen in Fig. 3 that $\tau_{\text {eff }}$ of doped and undoped RFSD a Si are in the same range with only slightly higher values provided by intrinsic layers. This suggests that the disorder related defects of the amorphous network are dominant and additional doping of the layer only has small influence on passiv ation quality.

Compared to the optimal deposition temperature of $\sim 225{ }^{\circ} \mathrm{C}$ of PECV deposited a Si:H layers (Ref. [52,61,62]), optimal RFSD tempera ture is $\sim 100{ }^{\circ} \mathrm{C}$ higher (Fig. 3(a)). Knights et al. (Ref. [63]) showed that the lowest hydrogen content embedded in an a Si:H layer deposit ed by a direct PECVD reactor is at a deposition temperature of around $225^{\circ} \mathrm{C}$. It can be assumed that this is based on a high uniformity of the amorphous network with small amount of defects. Therefore, it is con ceivable that a direct plasma deposition provides interactions between atoms at the surface of the growing layer and atoms in the plasma, like breaking up weak Si Si bonds. The plasma in the used sputter deposition reactor is located above and not in direct contact with the substrate. It can be assumed that the missing influence of direct plasma can be replaced by a higher deposition temperature finding an optimum at $325^{\circ} \mathrm{C}$. Temperatures above $325^{\circ} \mathrm{C}$ provide an epitaxial growth of the film and lower the passivation quality of the layer [11].

Fig. 3(b) shows the evaluation of the influence of layer thickness on passivation quality of (p) and (i) a Si layers deposited at $325^{\circ} \mathrm{C}$. While varying the layer thickness from $4 \mathrm{~nm}$ to $\sim 150 \mathrm{~nm}, \tau_{\text {eff }}$ improves first up to a maximum at $\sim 40 \mathrm{~nm}$ before $\tau_{\text {eff }}$ decreases. These findings also correlate to those given in (Ref. [11]) for directly hydrogenated RFSD a $\mathrm{Si}$.

The sputter process itself causes damage to the a Si bulk as well as to the a Si/c Si interface and the c Si by a high energy photon induced formation of defects [64]. Furthermore, it is known that defects in the a Si bulk limit $\tau_{e f f}$, as well as defects at the sharp a Si/c Si interface [64 67]. Referring to this, it can be assumed that there is an optimum be tween layer growth and sputter damage related defect recombination at a thickness of $\sim 40 \mathrm{~nm}$ of RFS deposited layers.

\subsection{Morphology of sputter deposited amorphous silicon}

\subsubsection{Microscopic investigations}

HR TEM investigations (Fig. 4a) illustrate the differences of c Si and a Si structures. Fig. 4 shows the HR TEM image of a hydrogen free RFS deposited a Si layer directly at the a $\mathrm{Si} / \mathrm{c} \mathrm{Si}$ interface. Atoms in c Si are homogenously allocated while a Si provides a random network. Differences are pointed out comparing the diffraction patterns of the crystalline and the amorphous sections. The periodic structure of c Si (Fig. 4b) yields spots in the diffraction pattern while a heterogeneous structure like a Si leads to a circular amplitude distribution (Fig. 4c) [28].

According to (Refs. [3,39,40,52]), the morphology of an a Si:H layer exhibits a non columnar structure during CVD (chemical vapor deposi tion) and a columnar one during a PVD (physical vapor deposition) process. If the sticking coefficient of the used process gas mix is high, surface mobility of the Si atoms is low. Atoms attach earlier in the grow ing a Si layer to their final position and a so called self shadowing effect arises. This effect supports a columnar growth of the amorphous network and chains and branches arise [3,52]. The RFSD of a Si layers 

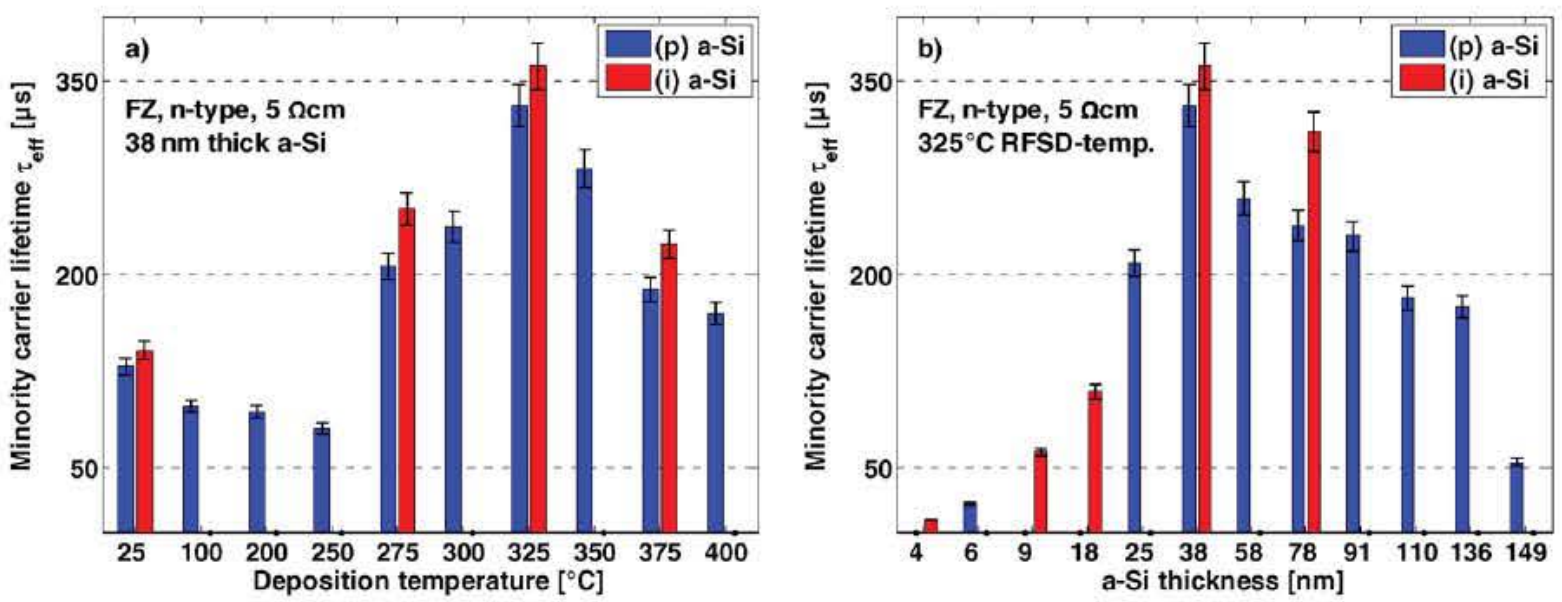

Fig. 3. (a): Minority carrier lifetime ( $\tau_{\text {eff }}$ ) of $38 \mathrm{~nm}$ thick (p) and (i) a-Si layers as a function of RFSD temperature. (b): Evaluation of $\tau_{\text {eff }}$ of (p) and (i) a-Si layers deposited at $325{ }^{\circ} \mathrm{C}$ with varying thicknesses.

is also a PVD driven process. This suggests that the here investigated a $\mathrm{Si}$ also grows in a columnar structure.

\subsubsection{Growth rate}

Fig. 5 compares the measured ( $)$ and the expected layer thick nesses of sputtered a $\mathrm{Si}$ (assuming a constant growth rate) and shows that there is a deviation from the bisectrix. The corresponding trend of growth rates ( $\mathbf{a}$ ) in consequence becomes not a constant value but a non linear function. As can be seen in Fig. 5, the growth rate starts at $\sim 3.8 \mathrm{~nm} / \mathrm{min}$ and decreases to $\sim 2.3 \mathrm{~nm} / \mathrm{min}$ at a desired layer thickness of $75 \mathrm{~nm}$. For thicker a Si layers, the growth rate is stable at $-2.3 \mathrm{~nm} / \mathrm{min}$. Within measurement accuracy, identical growth rates are found for doped and intrinsic a Si layers. This shows that the low amount of doping atoms, also dissociating from the target, does not affect the growth rate of the a Si layer. It can be assumed that primarily Si atoms can easily connect to the $c$ Si surface. Second, chains arise and the afore mentioned self shadowing effect increases, supporting the chain like growth of the amorphous network. Then the chains start to ramify, branches arise, and the growth rate reduces to a stable value.

Such a behavior correlates to the findings in Ref. [39] discussing the hydrogen depth profile of a columnar a Si:H layer. This further supports the assumption of a columnar growth of hydrogen free RFS deposited a Si.

It should be mentioned that the growth rates of RFS deposited a $\mathrm{Si}$ shown in Fig. 5 ( $\square$ ) are around ten times lower compared to those of PECV deposited a Si:H [39].

\subsubsection{Surface roughness}

Fig. 6 shows AFM topography images of $\sim 150 \mathrm{~nm}$ thick undoped and doped RFS deposited a Si directly after deposition and also after post hydrogenation ( $>10 \mathrm{~d}, 370^{\circ} \mathrm{C}, 1000 \mathrm{mTorr}$ ). Statistical evaluation of the RMS roughness $\left(R_{q}\right)$ (Ref. [68]) representing the standard deviation $(\sigma)$ of the topography as well as the probability densities $(p)$ are given in Fig. $6 \mathrm{c}$ and $\mathrm{f}$ for as deposited (blue) and post hydrogenated (red) (p) and (i) a Si layers.

The higher surface roughness of the as deposited samples is appar ent (Fig. 6a, d). Also visible are the larger structures and higher surface roughness of the (p) a Si layer d) (up to $\sim 20 \mathrm{~nm}$ ) compared to the intrinsic reference a) $(\sim 5 \mathrm{~nm})$. As can be seen in Fig. $6 \mathrm{a}$, the surface of (i) a Si forms nano sized structures during RFS deposition appearing like needles. These 'needles' are growing up to a few nanometers. In comparison, the doped layer (d) forms taller clusters of (p) a Si in the
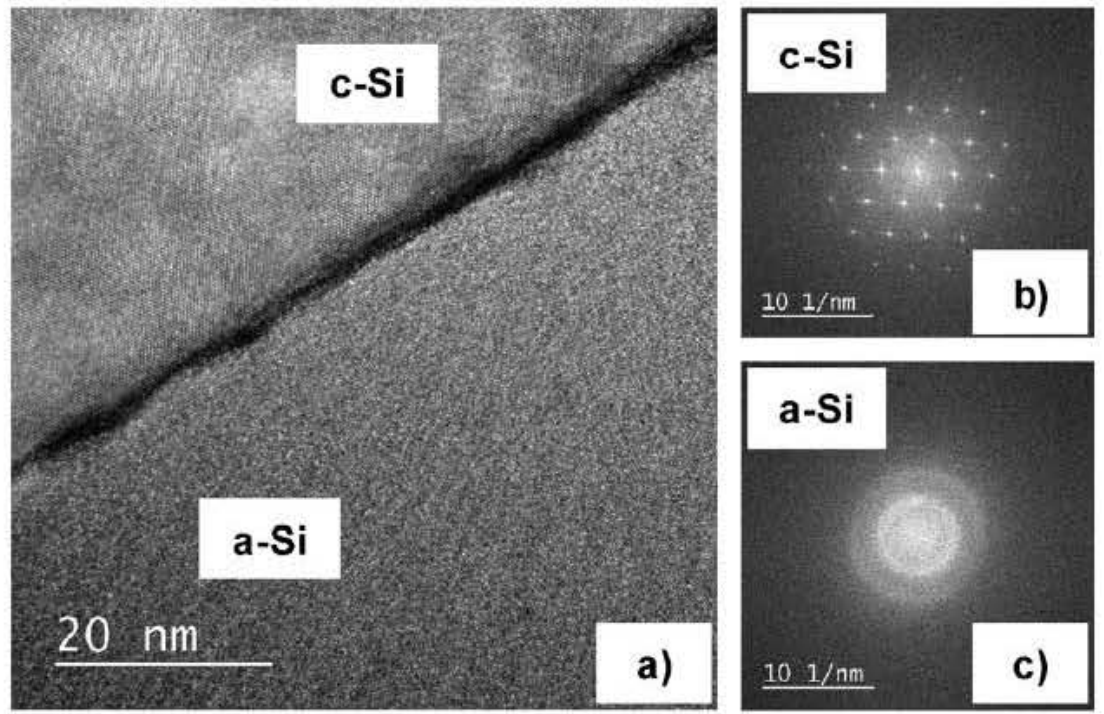

Fig. 4. (a) HR-TEM image of an RFS-deposited (p) a-Si/c-Si interface visualizing differences of a heterogeneous (a-Si) and a homogenous (c-Si) structure. (b and c) Diffraction pattern images of $\mathrm{c}-\mathrm{Si}$ ( $\mathrm{b}$, characteristic spots) and a-Si (c, circular amplitude distribution). 


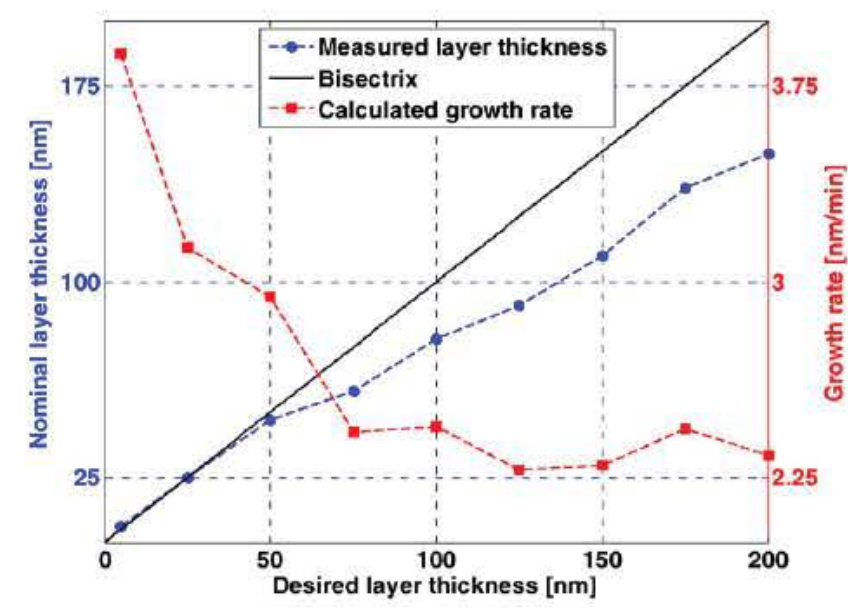

Fig. 5. Deviation of the nominal from desired layer thicknesses of boron doped RFS-deposited a-Si ( ) and calculated corresponding growth rates ( $(\mathbf{m})$.

range of almost $20 \mathrm{~nm}$. This also agrees with investigations published in Ref. [69] showing that boron doping of a Si leads to a rougher surface.

Boron embedded in the (p) a Si layer prevents the formation of fine structure because it does not take part in the aforementioned columnar growth process and shortens the chains and branches whereby a clus tered layer arises.

During post hydrogenation the surface roughness of the intrinsic a $\mathrm{Si}$ (b) decreases by $\sim 20 \%$ and the one of the doped a Si by $\sim 25 \%$ (e). This process occurs because hydrogen reorganizes the surface by breaking up weak Si Si bonds like it would happen in a PECVD reactor directly during deposition $[3,70]$ Nevertheless, surface roughness of a (p) a Si layer after post hydrogenation is higher compared to an as deposited (i) a Si layer.

Additional investigations of hydrogen free a Si layers treated only thermally at $370{ }^{\circ} \mathrm{C}$ without indirect hydrogen plasma show that stan dard deviation $(\sigma)$ of the roughness does not change during thermal treatment alone. This indicates that hydrogen is essential for lowering surface roughness by smoothening the surface in the way described above.

a)

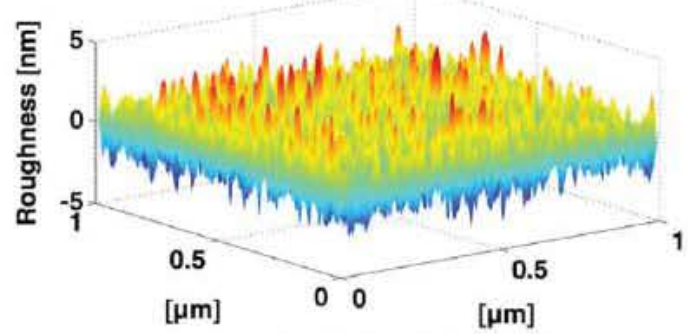

d)

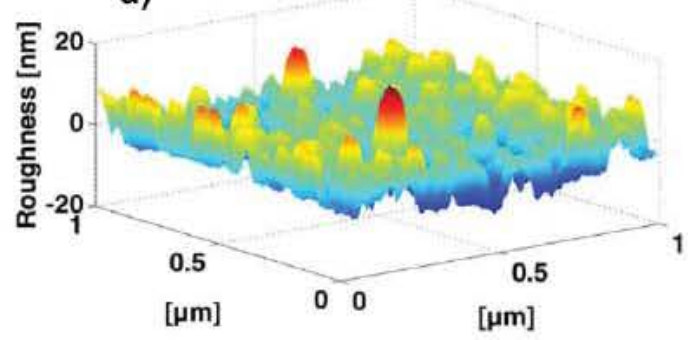

\subsection{Structural stability}

As shown in 3.3.1 by HR TEM investigations, the RFS deposited a Si layers are amorphous at the $\mathrm{Si} / \mathrm{c} \mathrm{Si}$ interface. Complementary and an other proof of the non crystallinity is Raman spectroscopy [30]. Investi gations are carried out using the same $\sim 150 \mathrm{~nm}$ thick RFS deposited amorphous layers investigated by AFM analysis in Section 3.3.3.

Fig. 7 illustrates a Raman spectrum of an as deposited layer as well as spectra measured after several durations of post hydrogenation at $370^{\circ} \mathrm{C}$. All spectra are normalized to the maximum of the transverse optic (TO) phonon band.

Due to the incorporation of hydrogen, there is a decrease in the strain of the amorphous structure during post hydrogenation and the intensity of the peaks of the TA, LA and LO bands also decrease [71]. The hydrogen induced improvement of the amorphous network leads to an apparent but small shift of the TO band towards $480 \mathrm{~cm}^{-1}$ [72]. As there is no arising in the intensities of the $\mu \mathrm{c} \mathrm{Si}\left(510 \mathrm{~cm}^{-1}\right)$ or c Si $\left(521 \mathrm{~cm}^{-1}\right)$ modes, the Raman crystallinity $\left(\Phi_{c}\right)$ stays at $\sim \%$ [32]. This shows that a post hydrogenation of up to $250 \mathrm{~h}$ at $370{ }^{\circ} \mathrm{C}$ does not affect $\Phi_{c}$ of the (i) a Si layers, Fig. 7.

Corresponding to the shown stable $\Phi_{c}$ of (i) a Si, (p) a Si layers also investigated preserve the stable $\Phi_{c}$ during post hydrogenation, too (not shown). This is not surprising because of the boron related disorder of the amorphous network [3].

Raman investigations demonstrate that there is no crystallization occurring during post hydrogenation $\left(\Phi_{c}=0 \%\right)$. Therefore, it can be concluded that the structure of the sputtered a $\mathrm{Si}$ is stable during the applied process of post hydrogenation. Moreover, it is shown that the (i) and (p) a Si surfaces investigated by AFM (Fig. 6) and the discussed nano sized structures are also amorphous.

\subsection{Band gap}

Evaluations of $E_{\text {Tauc }}$ (Ref. [31]) and $E_{04}$ (Ref. [37]) of RFS deposited a Si layers $(38 \mathrm{~nm})$ after several durations of post hydrogenation at $370{ }^{\circ} \mathrm{C}$ are presented in Table I.

$E_{\text {Tauc }}$ increases slightly during the first $0.16 \mathrm{~min} / \mathrm{nm}(6 \mathrm{~min})$ of post hydrogenation and remains constant during the ongoing post hydrogenation treatment. In contrast, $E_{04}$ increases with time and reaches $1.6 \mathrm{~min} / \mathrm{nm}$ of post hydrogenation the as deposited value of $E_{\text {Tauc }}$. After $\sim 60 \mathrm{~min} / \mathrm{nm}$ of post hydrogenation the calculated band b)

(i) a-Si post-hydrogenated

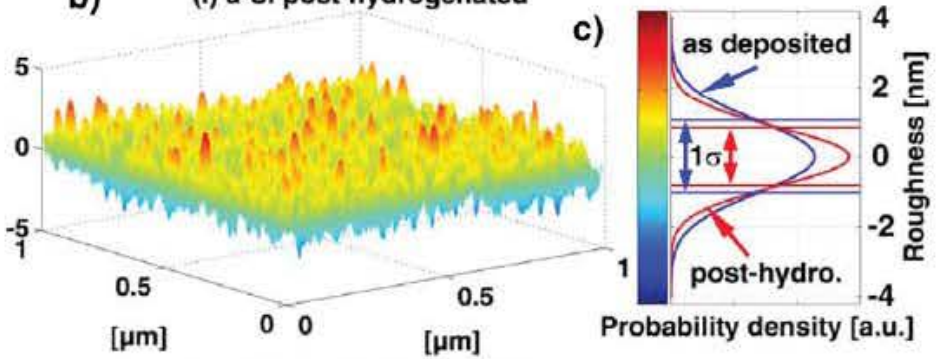

e)

(p) a-Si post-hydrogenated

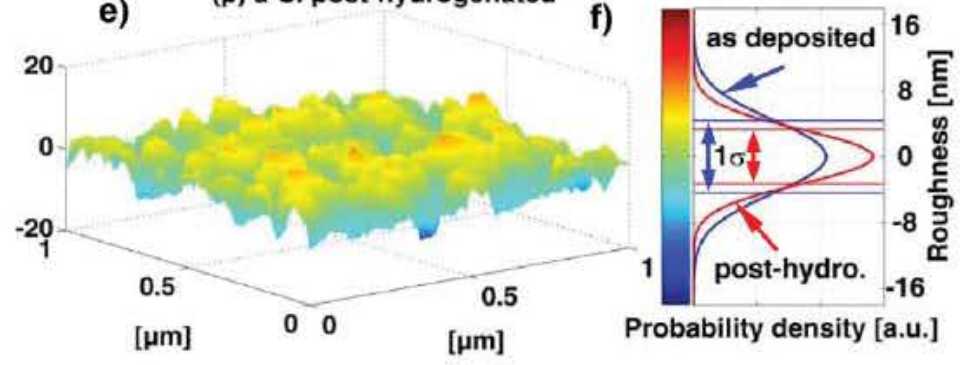

Fig. 6. Surface roughness of (i) and (p) a-Si samples directly after deposition and after thermal and hydrogen treatment (surface maps). Calculated probability densities and standard deviations of the samples are given on the right. 


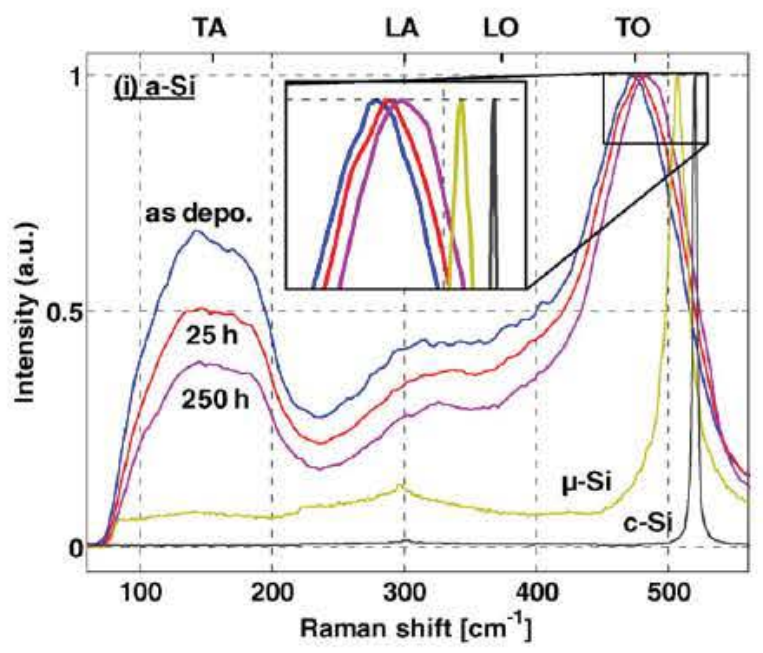

Fig. 7. Normalized Raman spectra of sputtered (i) a-Si after several durations of posthydrogenation compared to $\mu-\mathrm{Si}$ and $\mathrm{c}-\mathrm{Si}$.

gaps $E_{\text {Tauc }}$ as well as $E_{04}$ are nearly the same. In comparison to the mi nority carrier lifetime evaluation in Section 3.2, the measurement setup to determine the band gap is less sensitive than evaluating $\tau_{\text {eff }}$. While Fig. 2 shows that it needs more than $300 \mathrm{~min} / \mathrm{nm}$ to reach stable $\tau_{\text {eff }}$ values, the band gap $E_{04}$ remains stable after $\sim 64 \mathrm{~min} / \mathrm{nm}(>40 \mathrm{~h})$ and $E_{\text {Tauc }}$ after just $\sim 0.16 \mathrm{~min} / \mathrm{nm}(6 \mathrm{~min})$ of post hydrogenation.

The steady increase of $E_{04}$ suggests a decrease of the number of local ized states within the band gap. This occurs by hydrogen diffusion into the a Si layer saturating defects like dangling bonds or restructuring weak $\mathrm{Si} \mathrm{Si}$ bonds. This also agrees with the results of Raman spectro scopic investigations (Section 3.4) showing a decrease in defect density in the amorphous layer during post hydrogenation.

\subsection{Hydrogen content and silicon hydrogen bonding structure}

Fig. 8 shows the total concentration of hydrogen measured by NRRA (Ref. [3,39 41]) ( $\mathbf{\Delta}$ ) and the sum of measured Si $\mathrm{H}_{\mathrm{x}}$ bonds $(\bullet)$ measured by FTIR (Ref. [35,49,50]) of $154 \mathrm{~nm}$ thick RFS deposited a Si layers after several durations of post hydrogenation. The hydrogen content rises con tinuously with hydrogenation time (blue dashed line). Also, the content of $\mathrm{Si} \mathrm{H}_{\mathrm{x}}$ bonds increases during post hydrogenation $(\varpi, \bullet)$. Furthermore, the obviously high correlation in total hydrogen concentration measured by NRRA ( $\Delta$ ) and the one originating from $\mathrm{Si} \mathrm{H}_{\mathrm{x}}$ bonds $(\bullet)$ indicates less interstitial hydrogen in the post hydrogenated a Si layers.

$\mathrm{Si} \mathrm{H}_{2}$ bonds ( $\mathrm{w}$ ) become the dominant bond type during post hydrogenation and also increase faster with annealing time compared to the content of $\mathrm{Si}$ H bonds $(\bullet)$. A comparatively high ratio of $\mathrm{Si} \mathrm{H}_{2}$ in dicates a columnar morphology of the a Si layer and the formation of discontinuities like microvoids during deposition $[39,67,52]$.

Investigations of as deposited layers (not shown in Fig. 8) yield a hy drogen content of $\sim 0.5 \%$ (NRRA and FTIR). In addition, FTIR measure ments show that this initial content can be ascribed to $\mathrm{Si} H$ bonds while $\mathrm{Si} \mathrm{H}_{2}$ bonds are not detectable within measurement accuracy.

Table I

Band gap values $E_{T a u c}$ and $E_{04}$ of $38 \mathrm{~nm}$ thick RFS-deposited a-Si layers directly after deposition and after several durations of post-hydrogenation at $370^{\circ} \mathrm{C}$

\begin{tabular}{lll}
\hline Post-hydr, time & $\mathrm{E}_{\text {Tauc }}$ & $E_{04}$ \\
\hline As deposited & $1.76 \mathrm{eV}$ & $1.49 \mathrm{eV}$ \\
$0.16 \mathrm{~min} / \mathrm{nm}$ & $1.88 \mathrm{eV}$ & $1.54 \mathrm{eV}$ \\
$1.6 \mathrm{~min} / \mathrm{nm}$ & $1.86 \mathrm{eV}$ & $1.77 \mathrm{eV}$ \\
$7.9 \mathrm{~min} / \mathrm{nm}$ & $1.88 \mathrm{eV}$ & $1.81 \mathrm{eV}$ \\
$63 \mathrm{~min} / \mathrm{nm}$ & $1.89 \mathrm{eV}$ & $1.86 \mathrm{eV}$ \\
$100 \mathrm{~min} / \mathrm{nm}$ & $1.88 \mathrm{eV}$ & $1.86 \mathrm{eV}$ \\
\hline
\end{tabular}

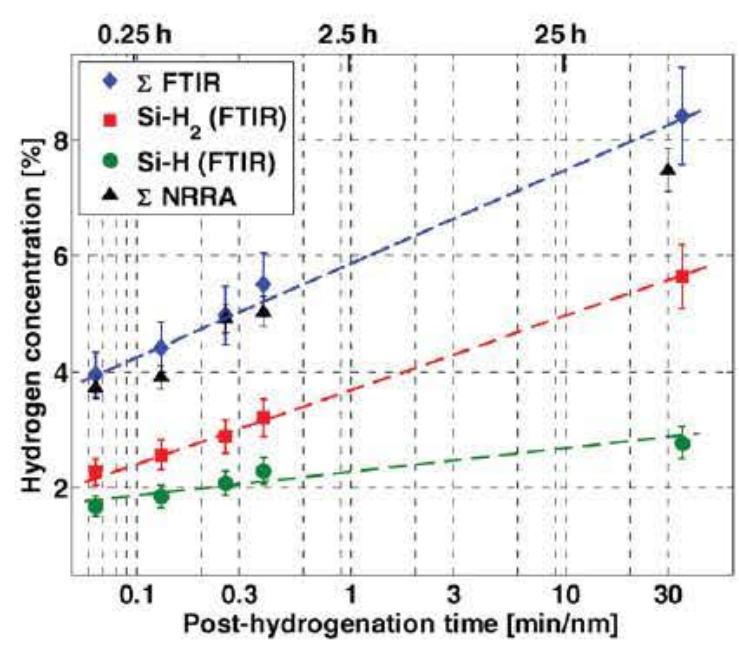

Fig. 8. Absolute hydrogen content as well as $\mathrm{Si}-\mathrm{H}_{\mathrm{x}}$ bonding concentrations of $154 \mathrm{~nm}$ RFSdeposited a-Si after several durations of post-hydrogenation investigated by FTIR and NRRA.

The marginal initial hydrogen content may originate from an adherence of hydrogen to the wafer and the carrier prior to deposition.

\subsection{Hydrogen diffusion}

Diffusion of hydrogen through the a Si layer is based on Fick's law and can be described by a complementary error function [3,51].

Fig. 9 shows the NRRA measured hydrogen depth profiles of RFS deposited (p) a Si directly after deposition and after several times of post hydrogenation at $370^{\circ} \mathrm{C}$ for different samples. Solid lines represent fitted diffusion profiles calculated by using Eq. (6). As marked in Fig. 9, four areas can be identified within the hydrogen depth profile.

Because of adherence of hydrogen to the sample surface, there is a signal directly in front and at the surface of the a Si layer, area (I). The high surface peak represents the interface to area (II). This area represents the surface roughness of the sample. As discussed in Section 3.3.3, surface roughness decreases during thermal and hydro gen treatment by reorganization of $\mathrm{Si} \mathrm{Si}$ bonds. Smoothing the surface also influences the hydrogen profile in this area.

As can be seen in Fig. 9, the hydrogen surface peak decreases togeth er with surface roughness during post hydrogenation. In the same time,

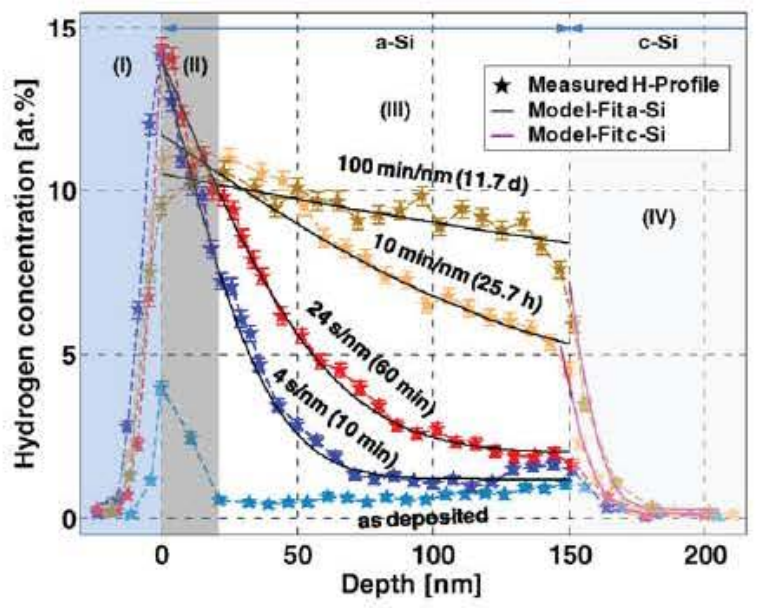

Fig. 9. NRRA hydrogen depth profiles measured directly after deposition and after several durations of post-hydrogenation, lines are guides to the eye. Four areas can be identified within the profiles: (I) a-Si surface, (II) surface roughness, (III) a-Si bulk, (IV) c-Si bulk. Fits of diffusion profiles after several durations of post-hydrogenation according to Fick's law. 
hydrogen content in the a Si bulk (III) increases. Hydrogen diffuses into the layer and passivates defects by saturating open $\mathrm{Si}$ bonds. The a $\mathrm{Si} / \mathrm{c}$ Si interface is the interface between area (III) and (IV), while area (IV) is the c Si bulk

The measured hydrogen distribution of an as deposited $(\star)$ sample shows an initial contamination of hydrogen. Omitting the surface peak, the hydrogen has its maximum in the region of area (III) directly at the a Si/c Si interface. The decrease in hydrogen content in area (III) in growth direction of the a Si layer supports the assumption of ad herence of hydrogen to the wafer and the sample carrier (Section 3.6).

As seen in Section 3.6, it can be assumed that all hydrogen is bonded to silicon atoms, interstitial hydrogen is not detectable within measure ment accuracy. In such a disordered structure diffusion of hydrogen oc curs by a trapping mechanism. During thermal and hydrogen treatment, bonded hydrogen can be released from $\mathrm{Si} \mathrm{H}_{\mathrm{x}}$ bonds and moves towards an interstitial site before reacting with dangling bonds or reorganizing weak Si Si bonds. According to (Ref. [3]) for trapping diffusion, the diffusion coefficient $D_{H}$ can be calculated as:

$D_{H} \quad 1 / 6 \quad a_{D}^{2} \quad \omega_{0} e^{\left(E_{H D} / k_{B} T\right)}$

considering the distance between sites $\left(a_{D}\right)$, the attempt to escape frequency $\left(\omega_{0} \sim 10^{13} \mathrm{~s}^{-1}\right)[3,73]$, the energy to release hydrogen from a $\mathrm{Si} \mathrm{H}_{\mathrm{x}}$ bond $\left(E_{H D}=1.1 \ldots 1.5 \mathrm{eV}\right)[3,74]$ and also Boltzmann constant $\left(k_{B}\right)$ and temperature $(T)$. Due to saturation of open bonds, the distance between sites $\left(a_{D}\right)$ decreases because less open sites are left $[3,73]$. Within this process the diffusion coefficient $D_{H}$ also decreases with post hydrogenation time, see Fig. 10.

Fig. 10 shows the evaluation of the diffusion coefficient $D_{H}$ of RFS deposited (p) a Si ( $\square$ ) as well as of (i) a Si (•) during post hydrogenation at $370{ }^{\circ} \mathrm{C}$. While the gradients of the diffusion coef ficients are the same for (p) and (i) a $\mathrm{Si}$ in a double logarithmic scale, the absolute values are lower for (i) a $\mathrm{Si}(\bullet)$.

Doping of a Si leads to additional open sites and a higher defect density compared to undoped a Si. The additional traps yield a higher diffusion velocity of hydrogen within and through the (p) a Si layer (Eq. (6)).

The diffusion coefficients found for (i) and ( $p$ ) a Si are in the range of those given in literature $[3,52,75]$. The diffusion coefficient of hydrogen in the transient section (Fig. 9 (area IV)) between a Si and c Si bulk is calculated using Eq. (5) to $5.4 \cdot 10^{-13} \mathrm{~cm} / \mathrm{s}$ after $10 \mathrm{~min} / \mathrm{nm}$ as well as after $100 \mathrm{~min} / \mathrm{nm}$ of post hydrogenation. This is similar to hydrogen dif fusion coefficients of FZ c Si given in Refs. [52 78].

\section{Conclusions}

The investigations in this study demonstrated that initially hydrogen less and non passivating intrinsic as well as doped a Si layers develop surface passivation properties during a post hydrogenation step in a MIRHP reactor at $370{ }^{\circ} \mathrm{C}$. The RFSD a Si deposited on $5 \Omega \mathrm{cm}$ FZ (n) c Si provides minority carrier lifetimes of up to $360 \mu$ s for $100 \mathrm{~min} / \mathrm{nm}$ post hydrogenated (i) a Si, while for (p) a Si a maximum of $330 \mu$ s is determined. These optimal lifetime values are achieved with layer thicknesses of $\sim 40 \mathrm{~nm}$ deposited at a temperature of $325^{\circ} \mathrm{C}$. This can be related to a decrease of localized states within the band gap. $E_{\text {Tauc }}$ as well as $E_{04}$ show the same value of $\sim 1.88 \mathrm{eV}$ after post hydrogenation. The surface roughness of the initially rough RFSD a Si decreases up to $25 \%$ during post hydrogenation while the Raman crystallinity remains at $0 \%$, indicating the stability of the amorphous network. NRRA measured hydrogen depth profiles and further investiga tions have identified trapping diffusion as the main diffusion mechanism in a Si. FTIR measurements have shown that no interstitial hydrogen exists in the post hydrogenated a Si layers while $\mathrm{Si} \mathrm{H}_{2}$ becomes the dominant bond type. This suggests a columnar growth of the RFS deposited a Si.

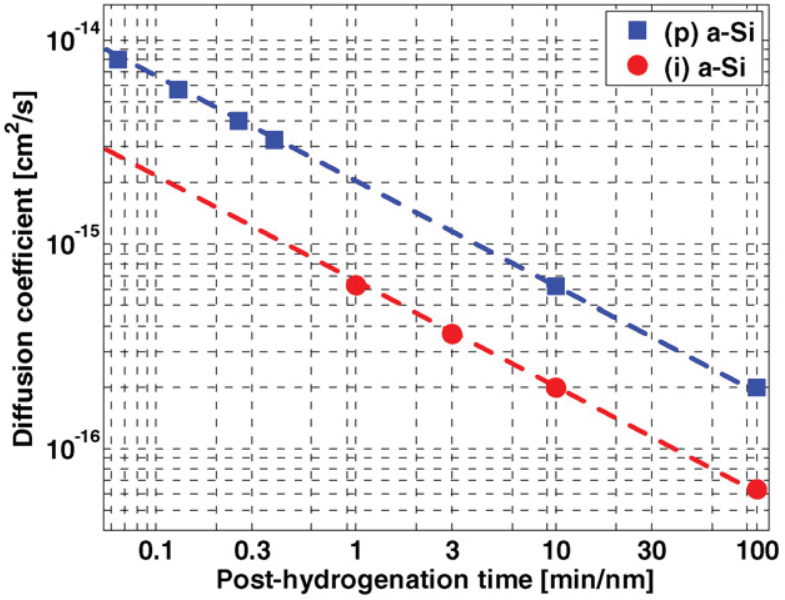

Fig. 10. Evaluation of hydrogen diffusion coefficients of (p) and (i) a-Si during post-hydrogenation at $370{ }^{\circ} \mathrm{C}$

\section{Acknowledgments}

Part of this work was supported by the German Federal Ministry for the Environment, Nature Conservation and Nuclear Safety (FKZ 0325581). The content is the responsibility of the authors. The authors would also like to thank the RUBION team at the Ruhr University of Bochum for operating the dynamitron tandem accelerator.

\section{References}

[1] N.M. Park, T.S. Kim, S.J. Park, Appl. Phys. Lett. 78 (2001) 2575

[2] R.A. Street, R. Hull, R.M. Osgood Jr., H. Sakaki, A. Zunger, Technology and Applications of Amorphous Silicon, Springer-Verlag, Berlin, 2000.

[3] R.A. Street, R.W. Cahn, E.A. Davis, I.M. Ward, Hydrogenated amorphous silicon, Cambridge University Press, Cambridge, 1991

[4] K.H. Cherenack, A.Z. Kattamis, B. Hekmatshoar, J.C. Sturm, S. Wagner, IEEE Electron Device Lett. 28 (2007) 1004.

[5] H. Stiebig, V. Mandryka, E. Bunte, H.-J. Büchner, K.H. Jun, G. Jäger, J. Optoelectron, J. Optoelectron. Adv. Mater. 5 (2003) 1305.

[6] K. Masuko, M. Shigematsu, T. Hashiguchi, D. Fujishima, M. Kai, N. Yoshimura, T. Yamaguchi, Y. Ichihashi, T. Mishima, N. Matsubara, T. Yamanishi, T. Takahama, M. Taguchi, E. Maruyama, S. Okamoto, IEEE J. Photovoltaics 4 (2014) 1433.

[7] E.C. Freeman, W. Paul, Phys. Rev. B 18 (1978) 4288.

[8] T.D. Moustakas, J. Electron. Mater. 8 (1979) 391

[9] A. Hargreaves, X. Zhang, A. Cuevas, D. Macdonald, Proceedings of the 28th EUPVSEC, Paris, France, 2013 1064-1067.

10] X. Zhang, A. Cuevas, B. Demaurex, S. De Wolf, Energy Procedia 55 (2014) 865.

111] X. Zhang S. Hargeaves, Y. Wan, A. Cuevas, Phys. Status Solidi (RRL) 8 (2014) 231.

[12] Y. Chiba, Y. Abe, M. Kawamura, K. Sasaki, Vacuum 83 (2008) 483.

[13] X. Zhang, A. Cuevas, Phys. Status Solidi 7 (2013) 619

[14] X. Zhang, A. Cuevas, A. Thomson, IEEE J. Photovoltaics 3 (2013) 183.

[15] A.V. Singh, S. Chandra, S. Kumar, G. Bose, J. Micromech. Microeng. 22 (2012) 025010.

[16] P.M. Kaminski, A. Abbas, K. Bass, G. Claudio, Energy Procedia 10 (2011) 71.

[17] Y.-H. Joung, H.I. Kang, J.H. Kim, H.-S. Lee, J. Lee, W.S. Choi, Nanoscale Res. Lett. 7 (2012) 1.

18] J. Catoir, W. Wolke, M. Grieshammer, R. Preu, R. Trassl, D. Grambole, Proceedings of the 23th EUPVSEC, Valencia, Spain, 2008 1530-1533.

[19] M.B. Takeyama, M. Sato, Y. Nakata, Y. Kobayashi, T. Nakamura, A. Noya, J. Appl. Psychol. 53 (2014) 5S2.

[20] S. Gloger, N. Brinkmann, B. Terheiden, Energy Procedia 8 (2011) 666

[21] S. Y. Choi, patent WO2012024114 (19 July 2012).

22] H. Hagleitner, Z. Ring, patent WO2014055315 (10 April 2014).

[23] D.K. Schroder, Semiconductor material and device characterization, John Wiley \& Sons, Inc., New Jersey, 2006.

[24] M. Spiegel, P. Fath, K. Peter, B. Buck, G. Willeke, E. Bucher, Proceedings of the 13th EUPVSEC, Nice, France, 1995 421-424.

[25] M. Mews, T.F. Schulze, N. Mingirulli, L. Korte, Appl. Phys. Lett. 102 (2013) 122106

[26] Y.L. Huang, E. Simoen, C. Claeys, J.M. Rafi, P. Clauws, R. Job, W.R. Fahrner, Appl. Phys. Lett. 89 (2006) 031911

[27] R. Job, W.R. Fahrner, A.G. Ulyashin, Mater. Sci. Eng. B73 (2000) 197.

[28] D.B. Williams, B. Carter, Transmission electron microscopy, Part 1-4, SpringerVerlag, New York, 2009

[29] G. Binning, C.F.G.C. Quate, Phys. Rev. Lett. 56 (1986) 930

[30] R. Al-Salman, J. Mallet, M. Molinari, P. Fricoteaux, F. Martineau, M. Troyon, S. Zein El Abedin, F. Endres, Phys. Chem. Chem. Phys. 10 (2008) 6233. 
[31] T. Deschaines, J. Hodkiewicz, P. Henson, Characterization of amorphous and microcrystalline silicon using raman spectroscopy, Thermo Fisher Scientific, Madison, 2009.

[32] C. Droz, E. Vallat-Sauvain, J. Bailat, L. Feitknecht, J. Meier, A. Shah, Sol. Energy Mater. Sol. Cells 81 (2004) 61.

[33] H.-S. Hwang, M.G. Park, H. Ruh, H. Yu, B. Kor, Chem. Soc. 31 (2010) 2909.

[34] J. Tauc, A. Menth, J. Non-Cryst. Solids 8 (1972) 569.

[35] N. Brinkmann, A. Gorgulla, A. Bauer, D. Skorka, G. Micard, G. Hahn, B. Terheiden, Phys. Status Solidi A 211 (2014) 1106.

[36] M. Taguchi, K. Kawamoto, S. Tsuge, T. Baba, H. Sakata, M. Morizane, K. Uchihashi, N. Nakamura, S. Kiyama, O. Oota, Prog. Photovolt. Res. Appl. 8 (2000) 503.

[37] A.S. Gudovskikh, J.-P. Kleider, E.I. Terukov, Физика и Техника Полупроводников (Physic and Semiconducters), 392005940.

[38] F. Giorgis, P. Mandracci, L. Dal Negro, C. Mazzoleni, L. Pavesi, J. Non-Cryst. Solids 266269 (2000) 588.

[39] S. Gerke, H.-W. Becker, D. Rogalla, G. Hahn, R. Job, B. Terheiden, Proceedings of the 29th EUPVSEC, Amsterdam, Netherlands, 2014 9-12.

[40] S. Gerke, H.-W. Becker, D. Rogalla, G. Hahn, R. Job, B. Terheiden, Morphology and hydrogen in passivating amorphous silicon layers, submitted to En. Proc, 2015.

[41] S. Gall, Ph. D. thesis, Technische Universität Berlin, Berlin, 1997.

[42] P.R. Hanley, M.R. Cleland, C.F. Mason, K.H. Morganstern, C.C. Thompson, IEEE Trans. Nucl. Sci. 16 (1969) 90.

[43] A. Benninghoven, F.G. Rüdenauer, H.-W. Werner, Secondary ion mass spectrometry: basic concepts, instrumental aspects, applications and trends, John Wiley \& Sons, New York, 1987.

[44] S. Flege, W. Ensinger, Mass spectrometry in semiconductor research, in handbook of mass spectrometry, John Wiley \& Sons, New York, 2012887.

[45] P. Danesh, B. Pantchev, K. Antonova, E. Liarokapis, B. Schmidt, D. Grambole, J. Baran, J. Phys. D. Appl. Phys. 37 (2004) 249.

[46] U. Reinholz, H.-P. Weise, K.-W. Brzezinka, W. Bremsere, BAN-S110, (German Federal Institute for Materials Research and Testing (BAM), Berlin, 2004.

[47] W.R. Fahrner, M. Mühlbauer, H.C. Neitzert, D. Fisher, R.P. Agarwala, Silicon heterojunction solar cells, Trans Tech Publications, Zürich, 2006.

[48] W.A. Lanford, Nucl. Inst. Methods 149 (1978) 1.

[49] D. Suwito, Ph. D. thesis, University of Konstanz, Konstanz (2010).

[50] A.A. Langford, M.L. Fleet, B.P. Nelson, Phys. Rev. B 45 (1992) 13367.

[51] A. Fick, Ann. Phys. 170 (1855/2006) 59.

[52] J.I. Pankove, N.M. Johnson, R.K. Willardson, A.C. Beer, Hydrogen in semiconductors, Academic Press, San Diego, 1991.

[53] A. Eicke, G. Bilger, Fresenius J. Anal. Chem. 341 (1991) 214.
[54] G. Brechmann, W. Dzieia, E. Hörnemann, H. Hübscher, D. Jagla, J. Klaue, Elektrotechnik Tabellen Energieelektronik Industrieelektronik, Westermann Schulbuchverlag GmbH, Braunschweig, 1996.

[55] M.M. de Lima Jr, F.L. Freire Jr., F.C. Marques, Braz. J. Phys. 32 (2002) 379.

[56] S. Dauwe, J. Schmidt, R. Hezel, Proceedings of the 29th IEEE PVSC, New Orleans, USA, 2002 1246-1249.

[57] S. Gatz, H. Plagwitz, P.P. Altermatt, B. Terheiden, R. Brendel, Appl. Phys. Lett. 93 (2008) 173502

[58] F.N. Fritsch, R.E. Carlson, SIAM J. Numer. Anal. 17 (1980) 238

[59] A. Gorgulla, N. Brinkmann, A. Bauer, G. Hahn, B. Terheiden, Proceedings of the 28th EUPVSEC, Paris, France, 2013 744-747.

[60] A. Richter, J. Benick, M. Hermle, S.W. Glunz, Proceedings of the 24th EUPVSEC, Hamburg, Germany, 2009 1534-1538.

[61] J. Mitchell, D. MacDonald, A. Cuevas, 44th Australian and New Zealand Solar Energy Society Conference, Canberra, Australia, 2006.

[62] M. Tucci, L. Serenelli, Thin Solid Films 516 (2008) 6939.

[63] J.C. Knights, G. Lucovsky, CRC Cr. Rev. Sol. State 9 (1980) 211.

[64] D. Skorka, N. Brinkmann, A. Gorgulla, G. Hahn, B. Terheiden, Proceedings of the 28th EUPVSEC, Paris, France, 2013 1162-1165.

[65] T.F. Schulze, H.N. Beushausen, C. Leendertz, A. Dobrich, B. Rech, L. Korte, Appl. Phys. Lett. 96 (2010) 252102.

[66] S. De Wolf, M. Kondo, Appl. Phys. Lett. 90 (2007) 042111.

[67] S. Gerke, A. Herguth, N. Brinkmann, G. Hahn, R. Job, Proceedings of the 28th EUPVSEC, Paris, France, 2013 2600-2603.

[68] J.D. Miller, S. Veeramasuneni, J. Drelich, M.R. Yalamanchili, G. Yamauchi, Polym. Eng. Sci. 36 (1996) 1849

[69] T. Toyama, W. Yoshida, Y. Sobajima, H. Okamoto, J. Non-Cryst. Solids 354 (2008) 2204

[70] D.M. Tanenbaum, A.L. Laracuente, A. Gallagher, Phys. Rev. B 56 (1997) 4243.

[71] K. Shrestha, V.C. Lopes, A.J. Syllaios, C.L. Littler, J. Non-Cryst. Solids 403 (2014) 80

[72] A.T. Voutsas, M.K. Hatalis, J. Boyce, A. Chiang, J. Appl. Phys. 78 (1995) 6999.

[73] A.J. Flewitt, S. Lin, W.I. Milne, R.B. Wehrspohn, M.J. Powell, J. Non-Cryst. Solids 352 (2006) 1700

[74] R. Rizk, P. de Mierry, D. Ballutaud, M. Aucouturier, Phys. Rev. B 44 (1991) 6141.

[75] J. Kakalios, R.A. Street, W.B. Jackson, Phys. Rev. Lett. 59 (1987) 1037.

[76] C.P. Herrero, M. Stutzmann, A. Breitschwerdt, P.V. Santos, Phys. Rev. B 41 (1990) 1054.

77] D. Mathiot, Phys. Rev. B 40 (1989) 5067.

[78] Y.L. Huang, B. Wdowiak, R. Job, Y. Ma, W.R. Fahrner, J. Electrochem. Soc. 151 (2004) G564. 